\title{
A "parceria" entre a ONG GAJOP e o Estado na execução do Programa de Proteção a Testemunhas
}

\section{A partnership between the State and the GAJOP NGO to developed a program to protection attestant}

\author{
Flávia da Silva Clemente* \\ Rosineide Meira Cordeiro* \\ Sandra Maria Batista Silveira**
}

\begin{abstract}
Resumo: No presente artigo analisaremos a execução do Programa de Proteção a Vítimas e Testemunhas Ameaçadas de Morte (Provita) brasileiro, que foi formulado e executado pela organização não governamental, Gabinete de Assessoria Jurídica às Organizações Populares (GAJOP). Seu objetivo principal foi conhecer como os elementos do ideário neoliberal estão expressos nessa execução do Provita, que por meio de uma análise documental, concluímos pela necessidade de realização de mudanças no programa.
\end{abstract}

Palavras-chaves: Neoliberalismo. Estado. Sociedade Civil. Provita.

\begin{abstract}
In this article we will analyze the implementation of a Protection Program for victims and witnesses threatened with death (PROVITA), created and developed in Brazil by GAJOP, a non-governmental organization that works with legal counsel for popular organizations. The main objective of this article is to understand how the elements of neoliberal ideas are expressed in PROVITA's implementation. Document analysis was the methodological choice used, which points the need to make change in the program.
\end{abstract}

Keywords: Neoliberalism, State and civil society.

Recebido em: 11/11/2011. Aceito em: 20/11/2012.

\footnotetext{
* Possui Graduação em Serviço Social pela Universidade Federal de Pernambuco, pós-graduação em saúde pública pela FIOCRUZ. Mestre em Serviço Social pela Universidade Federal de Pernambuco. Professora do Departamento de Serviço Social da UFPE. Email: flaviaclemente2000@yahoo.com.br

"* Possui graduação em Serviço Social pela Fundação Universitária de Apoio ao Ensino Pesquisa e Extensão, mestrado em Serviço Social pela Universidade Federal de Pernambuco e doutorado em Psicologia pela Pontifícia Universidade Católica de São Paulo. Professora adjunta do Departamento de Serviço Social da Universidade Federal de Pernambuco, professora do Programa de Pós-graduação em Psicologia da UFPE. Email: rocordeirope@hotmail.com.

"*** Possui graduação em Serviço Social, mestre em Serviço Social pela Universidade Federal de Pernambuco, doutoranda em Serviço Social pela Universidade Federal de Pernambuco, professora assistente do curso de graduação em Serviço Social pela Universidade Federal de Pernambuco. Email: sanmaria@hotmail.com
} 


\section{Introdução}

No Brasil, o surgimento do Programa de Proteção a Vítimas e Testemunhas Ameaçadas de Morte (Provita) se vincula diretamente à atuação do Gabinete de Assessoria Jurídica às Organizações Populares (GAJOP), Organização não governamental (ONG), que elaborou, colocou em prática e propôs ao Estado Brasileiro a incorporação do programa citado como modelo para o desenvolvimento das ações voltadas para a proteção de testemunhas ${ }^{1}$.

Este artigo apresenta parte dos resultados obtidos da pesquisa realizada no programa de Mestrado em Serviço Social na Universidade Federal de Pernambuco (UFPE), acerca da execução por entidade da sociedade civil organizada, do Programa de Proteção a Vítimas e Testemunhas Ameaçadas de Morte no estado de Pernambuco, num contexto neoliberal.

Tendo identificado que o neoliberalismo no Brasil e o Provita estão inseridos no mesmo contexto histórico, e compreendendo que o advento desse ideário em nosso país favoreceu que tal programa de proteção se tornasse uma realidade, surgiu a pergunta da pesquisa: Como os elementos do ideário neoliberal estão expressos na execução do Provita?

Assim, destaca-se que conhecer de que forma os elementos do ideário neoliberal estão expressos na execução do Provita se configura no objetivo principal da pesquisa em tela.

A pesquisa de cunho qualitativa teve como material para coleta das informações documentos de domínio público e privado, sendo eles: folders de divulgação da Provita elaborados pelo GAJOP; Estatuto do GAJOP; Relatórios institucionais avaliativos sobre o Provita e Convênios entre Estado e a ONG GAJOP para execução do Provita e Legislação específica que regulamenta o Provita: Lei 9.807/99 e Decreto-lei 3.518/2000. A análise das informações coletadas foi inspirada na teoria da análise do discurso, a partir dos

\footnotetext{
1 Destaca-se que o Provita existe em 17 estados da federação (Acre, Alagoas, Amazonas, Bahia, Ceará, Distrito Federal, Espírito Santo, Goiás, Maranhão, Mato Grosso do Sul, Minas Gerais, Paraná, Pernambuco, Rio de Janeiro, Rio Grande do Norte, São Paulo e Santa Catarina), entretanto sua origem ocorreu no estado de Pernambuco a partir da ONG GAJOP, bem como sua expansão no Brasil contou com a importante participação dessa entidade.
}

fundamentos marxistas abordados por Michel Pêcheux.

Este artigo está dividido em cinco partes. $\mathrm{Na}$ primeira parte abordamos o neoliberalismo e seus principais aspectos, na segunda descrevemos acerca da história da ONG GAJOP, em seguida efetuamos uma abordagem sobre a relação desta e o surgimento do Provita, bem como expomos sobre aspectos centrais dessa política pública e na última parte refletimos sobre as implicações institucionais geradas na ONG, para que a partir desta haja execução de uma política pública de segurança e de direitos humanos.

\section{O neoliberalismo: principais aspectos}

No decorrer da década de 1990 vivenciamos na sociedade brasileira o incremento acelerado do ideário neoliberal. Nessa seara frisamos de acordo com Anderson (1995) que o neoliberalismo se origina após a Segunda Guerra Mundial, em regiões da Europa e da América do Norte onde o capitalismo atuava tendo como principal expoente Friedrich August von Hayek², que em 1947 articula, em Mont Pèlerin na Suiça, reuniões para realização de debates teóricos entre liberais que partilham do mesmo ideário, dentre os quais cita-se: Milton Friedman, R. Aron, L. Baudin, Ludwig von Mises entre outros.

Destaca-se que as reuniões deram origem posteriormente à sociedade do Mont Pèlerin, cujos membros mantinham reuniões internacionais a cada dois anos e desde a época de sua criação tinha o propósito, conforme descrito por Anderson (1995), de preparar as bases de um capitalismo regido pelas regras do mercado, indo de encontro ao momento histórico de forte regulação do mercado pelo Estado.

Sublinhamos que mesmo num contexto adverso às ideias neoliberais, Friedrich Hayek, em 1944, publica o livro O caminho da servidão, em que tece críticas à regulação do mercado pelo Estado, principalmente as economias socialistas a fim de justificar a tese de que o Estado tem

\footnotetext{
2 Doutor em direito e em ciências políticas foi diretor do Instituto Austríaco de Pesquisas Econômicas, Professor de Ciências Sociais e Morais da Universidade de Chicago. Professor emérito da Universidade Albert-Ludwigs de Freiburg, na Alemanha, bem como da Universidade de Chicago e ganhador do Prêmio Nobel de economia em 1974.
} 
papel limitado, com o mercado se configurando no espaço legítimo para o exercício da liberdade.

Porém, o autor admite a intervenção e controle do Estado quando este se destina a auxiliar o funcionamento da concorrência. Como exemplo, relata que a proibição de substâncias tóxicas, a limitação das horas de trabalho e o desenvolvimento de um sistema de serviços sociais são compatíveis com a concorrência, desde que as vantagens obtidas sejam maiores do que os custos sociais decorrentes dessas medidas, e que os serviços sociais oferecidos não tornem ineficaz a concorrência nos diversos setores da economia.

Por esse prisma, é perceptível que no neoliberalismo o Estado tem papel definido e limitado, no qual fica evidenciado que deve intervir apenas onde o mercado não possa incidir, desempenhando uma tarefa complementar. Sobre essa questão Hayek (1994) relata que:

O Estado deve limitar-se a estabelecer normas aplicáveis a situações gerais, deixando os indivíduos livres em tudo que depende das circunstâncias de tempo e lugar, porque só os indivíduos poderão conhecer plenamente as circunstâncias relativas a cada caso e a elas se adaptarem (p. 88).

Coadunando com os mesmos pressupostos defendidos por Hayek, outro importante teórico neoliberal, Milton Friedman, economista norte-americano e principal teórico da escola monetarista, que por meio de seus escritos ${ }^{3}$, deixa registrada sua defesa ao capitalismo competitivo ou concorrencial.

Friedman (1988) afirma que o capitalismo competitivo reúne as características para promover a liberdade política e econômica por separar o poder político e econômico permitindo que um controle o outro. Nesse âmbito, tece crítica à intervenção do Estado na economia como uma ameaça a essa liberdade.

Esse autor relata que só existem dois meios de coordenar as atividades econômicas: uma exercida pelos Estados totalitários, mediante direção centralizada e da coerção e a

\footnotetext{
${ }^{3}$ Principais obras desse autor foram Essays in Positive Economics (escrito em 1953), Capitalismo e Liberdade (escrito em 1962), A Monetary History of United States (escrito em 1963) e Inflation, Causes and Consequences (escrito em 1963).
}

outra exercida pelo mercado que se embasa na cooperação voluntária dos indivíduos.

Nesse contexto, o autor opta pela coordenação exercida pelo mercado, por entender que a preservação da liberdade requer a eliminação da concentração de poder, bem como a dispersão e distribuição de todo o poder que não tiver condições de ser eliminado. Isso demonstra que nesse âmbito um governo se faz necessário, pois um mercado livre que garante a liberdade tem apenas a função de reduzir as questões que devem ser decididas pelos meios políticos, e não de decidir e resolver todas as questões, dessa forma, o Estado teria uma função a desempenhar.

Sobre esse aspecto, o autor descreve, resumidamente, que em uma sociedade de mercado livre, as funções do governo se limitariam aos seguintes âmbitos:

Um governo que mantenha a lei e a ordem; defina os direitos de propriedade; sirva de meio para modificação dos direitos de propriedade e de outras regras do jogo econômico; julgue disputas sobre a interpretação das regras; reforce contratos; promova a competição; forneça uma estrutura monetária; envolva-se em atividades para evitar monopólio técnico e evite os efeitos laterais considerados suficientemente importantes para justificar a intervenção do governo; suplemente a caridade privada e a família na proteção do irresponsável, quer se trate de um insano ou de uma criança; um tal governo teria, evidentemente importantes funções a desempenhar. (p. 39).

Friedman (1988) entende que quanto maior inserção o Estado tiver na economia, maior será a ameaça à liberdade por substituir a cooperação voluntária pela coerção. Mas por outro lado, também descreve que do ponto de vista liberal essa cooperação voluntária pode ser substituída pela coerção ou ação compulsória do Estado apenas quando se destina à diminuição da pobreza.

Dito isto, identifica-se que o neoliberalismo durante a crise do capital ocorrida na década de 1970 se mostra pela primeira vez, desde suas origens, como uma alternativa viável para que o modo de produção capitalista possa permanecer garantindo sua reprodução.

No que se refere à questão do papel do Estado na perspectiva do ideário neoliberal 
destacamos de Anderson (1995) a seguinte opinião:

Foi uma reação teórica e política veemente contra o Estado Intervencionista e de bemestar [...] Trata-se de um ataque apaixonado contra qualquer limitação dos mecanismos de mercado por parte do Estado, denunciadas como ameaça letal à liberdade, não somente econômica, mas também política. (p. 09).

Esse autor destaca que apesar do evidente limite neoliberal em conseguir, ao menos no que se refere aos países de capitalismo avançado em 1980, alcançar seu objetivo principal de propiciar a restituição das taxas de crescimento estáveis, mediante medidas de deflação, ampliação da desigualdade, desemprego e contenção dos salários, o ideário neoliberal não propiciou, entre as décadas de 1970 e 1980, nenhum aumento na taxa de crescimento dos países integrantes da Organização Europeia para o Comércio e Desenvolvimento (OECD).

Mesmo com a constatação de que economicamente o ideário neoliberal não foi capaz de gerar crescimento econômico nos países da OECD, seus pressupostos permaneceram sendo válidos para serem implementados em toda a América latina, que se configurou, de acordo com o autor, na terceira grande cena de experimentações neoliberais.

Para tanto, o Consenso de Washington ${ }^{4}$ desempenhou importante papel no desenvolvimento do ideário neoliberal na América Latina, por ser composto de orientações de cunho economicista, quais sejam: disciplina fiscal; redução dos gastos; reforma tributária; juros de mercado; câmbio de mercado; abertura comercial; investimento estrangeiro direto; desregulação e direito de Propriedade ${ }^{5}$, que orientava esses países sobre os caminhos que deveriam adotar para atingirem eficácia fiscal que os possibilitaria sobrepujar as dificuldades econômicas em que vivenciavam.

Isso se dá devido ao fato de que em 1989 ocorreu na cidade de Washington uma reunião

\footnotetext{
4 Expressão dita pela primeira vez pelo economista John Williamson do International Institute for Economy em 1989.

${ }^{5}$ Dados obtidos no site: <www.funcex.com.br/bases/64 - Consenso\%20>. Sobre o Consenso Original de Washington de 1989, Jonh Williamson, What Washington Means Policy Reform, 1990.
}

de economistas integrantes dos organismos financeiros internacionais como o Fundo Monetário Internacional (FMI) e o Banco Interamericano de Desenvolvimento (BID), com o objetivo de discutir e elaborar propostas para implementação de reformas macroeconômicas para a América Latina, na perspectiva que se retomasse o desenvolvimento econômico.

Estas orientações foram adotadas pelo FMI como política oficial para os países da América Latina, e devido à grande influência que esse órgão exerce sob estes países pela vinculação financeira decorrente dos empréstimos contraídos, houve de fato uma orientação neste sentido de que as definições emitidas no Consenso de Washington fossem seguidas.

O que consideramos como mais importante sobre esse momento é a ciência que o neoliberalismo não foi uma iniciativa na América Latina desprovida de interesses externos e internos. Além disso, sublinhamos que apesar das experiências neoliberais nos países de capitalismo avançado, durante a década de 1980 , não ter atingido seu objetivo principal na elevação da taxa de crescimento, conseguiram êxito ideológico e político, de acordo com Anderson (1995):

[...] Economicamente, o neoliberalismo fracassou, não conseguiu nenhuma revitalização básica do capitalismo avançado. Socialmente, ao contrário, o neoliberalismo conseguiu muitos de seus objetivos, criando sociedades marcadamente mais desiguais, embora não tão desestatizadas como queria. Política e ideologicamente, todavia, o neoliberalismo alcançou êxito num grau com o qual seus fundadores jamais sonharam, disseminando a simples ideia de que não há alternativas para os seus princípios, que todos, seja confessando ou negando, têm de adaptar-se a suas normas. (p. 23).

\section{O neoliberalismo no Brasil: consolidação na gestão FHC}

O auge do ideário neoliberal no Brasil ocorreu na década de 1990, culminando num redimensionamento do papel do Estado no que se refere a suas responsabilidades constitucionais.

Sobre esse assunto, destaca-se que, Fernando Collor de Melo (1990 até o impeachment em 1992) e Fernando Henrique Cardoso (1994 
a 2001) exerceram papel fundamental durante seus respectivos governos na implementação do ideário neoliberal no Brasil.

Essa fase específica da história do Brasil torna-se necessária sua alusão porque se configurou no momento em que oficialmente o Provita iniciava, tendo sido posteriormente apoiado pelo Estado, e também foi o período em que o neoliberalismo brasileiro conseguiu se desenvolver de maneira promissora, vez que seus pressupostos foram amplamente desenvolvidos, como narra Behring (2003):

Por dentro das disputas de projetos societários de resposta para a crise econômica e o restabelecimento da democracia, vai se configurando a derrota de uma agenda progressista para o Brasil e a afirmação das chamadas 'reformas orientadas para o mercado'. Se as classes dominantes estiveram fragmentadas durante algum tempo, a coalizão em torno de Cardoso, após a aventura 'colorida', configurou uma recomposição burguesa duradoura no país, apesar das tensões e fissuras internas, que se tornaram públicas e evidentes no segundo mandato de Cardoso, e que estiveram na base da vitória eleitoral de um projeto democrático-popular nas eleições gerais de 2002. O controle inflacionário, após anos de instabilidade, gerou a base econômica e ideológica para a legitimação política do novo núcleo de poder no país a partir de 1994, que vai desencadear o ajuste neoliberal de forma mais intensa e profunda que Collor, em especial com a autorreferida 'reforma do Estado'. (p. 27).

Nesse intuito, um documento de extrema relevância para a consolidação do ideário neoliberal no Brasil foi o Plano Diretor de Reforma do Aparelho do Estado (PDRAE) do Ministério da Administração e Reforma do Estado (Mare), organizado pela equipe econômica comandada pelo Ministro da Administração Federal e Reforma do Estado, Luís Carlos Bresser Pereira, e aprovado pela Câmara de Reforma do Estado, em 21 de setembro de 1995, e posteriormente pelo presidente Fernando Henrique Cardoso.

No PDRAE (1995) também encontra-se explícito que o Estado deve rever suas funções, no que concerne ao âmbito econômico e social, distanciando-se da intervenção direta sob estes, conforme podemos ler a seguir:
A reforma do Estado deve ser entendida dentro do contexto da redefinição do papel do Estado, que deixa de ser o responsável direto pelo desenvolvimento econômico e social pela via da produção de bens e serviços, para fortalecer-se na função de promotor e regulador desse desenvolvimento. (p. 12).

Neste âmbito se torna fático destacar que o PDRAE (1995) distingue quatro setores do Estado: Núcleo Estratégico; Atividades Exclusivas; Serviços Não Exclusivos e Produção de Bens e Serviços para o Mercado.

Ressaltamos que será no Setor de Serviços Não Exclusivos, que poderemos ter a noção exata do espaço reservado pelo PDRAE (1995) para as entidades da sociedade civil, favorecendo que estas possam desempenhar um papel de executor de ações que outrora era de responsabilidade do Estado.

Ainda nesse aspecto, percebemos que também ficam estabelecidas as possibilidades de se firmarem "parcerias" entre o Estado e as entidades da sociedade civil, conforme está estabelecido no PDRAE (1995), no subitem referente aos Setores do Estado e Formas de Propriedade, onde se lê:

[...] é constituída pelas organizações sem fins lucrativos [...] favorece a parceria entre sociedade e Estado. [grifo nosso]. As organizações nesse setor gozam de autonomia administrativa muito maior que aquela possível dentro do aparelho do Estado. Em compensação seus dirigentes são chamados a assumir uma responsabilidade maior, em conjunto com a sociedade, na gestão da instituição. (p. 43).

Diante desta realidade, as entidades da sociedade civil passam a ser inseridas no projeto neoliberal brasileiro como integrante do setor de Serviços Não Exclusivos do Estado, e executarão, então, as atribuições, principalmente de vertente social, que anteriormente era função estatal. As parcerias são firmadas e essa situação oportuniza a concretização do Estado mínimo, no que se referem principalmente às políticas sociais públicas.

Gostaríamos de ressaltar que as organizações não governamentais, que nasceram apoiando os movimentos sociais da década de 1970 e 1980, possuem neste contexto um papel de destaque por ter, justamente, esse histórico de 
luta. Mas por outro lado a empreitada neoliberal também ocasiona uma forte crise nestas organizações, que passam a sofrer condicionantes do Estado para conseguir acessar financiamentos a seus projetos, tornando-as, muitas vezes, organizações instrumentalizadas pelos interesses estatais. Sobre esse tema Montaño (2002), destaca que:

As chamadas organizações não governamentais (ONGs), quando hoje passam a ser financiadas por entidades, muitas destas de caráter governamental, por meio de parcerias, ou quando são contratadas pelo Estado (federal, estadual, municipal), para desempenhar, de forma terceirizada, as funções a ele atribuídas, não parecem tão fiéis a seu dito caráter 'não governamental' e à sua condição de 'autogovernada'. Efetivamente, o Estado, ao estabelecer 'parceria' com determinada ONG e não com outra, ao financiar uma, e não outra, ou destinar recursos a um projeto, e a outro não, está certamente desenvolvendo uma tarefa seletiva, dentro e a partir da política governamental, o que leva tendencialmente à presença e permanência de certas ONGs e não outras, e determinados projetos e não outros. (p. 57).

Avaliamos neste bojo que o autor consegue explicitar as dificuldades atuais das ONGs e as pressões que estas permanecem vivenciar para conseguir cumprir com sua agenda de lutas.

Entretanto é importante sublinhar que as organizações não governamentais que se distinguem das demais por seus históricos compromissos com as lutas populares não devem ser caracterizadas e nem analisadas da mesma maneira daquelas que atuam com o Estado de forma acrítica e apolítica, apesar de vivenciar condicionantes estatais semelhantes.

Gostaríamos de nos referir, ainda, à crítica que Behring (2003) tece sobre a concepção de reforma do Estado, presente no Brasil durante a década de 1990. São considerações pertinentes, com as quais concordamos, tornando-se essencial apresentá-las para obtermos um prisma diferenciado do que está posto pelo PDRAE como sendo a solução para impulsionar o desenvolvimento social e econômico do nosso país. Isto posto, essa autora descreve que:

[...] chama a atenção a explicação da crise contemporânea como crise do ou localizada no Estado. Aí estão indicadas suas causas e suas saídas, o que expressa uma visão unilateral e monocausal da crise contemporânea [...] Em outra perspectiva - a da crítica marxista da economia política [...] tem-se que as mudanças em curso passam por uma reação do capital ao ciclo depressivo aberto no início dos anos 70, que pressiona por uma refuncionalização do Estado, a qual corresponde a transformações no mundo do trabalho e da produção, da circulação e da regulação. [...] as tentativas de retomada de taxas de lucro [...] ocorrem hoje por três eixos, que se articulam visceralmente: a reestruturação produtiva, uma rearticulação do mercado e o neoliberalismo. (p. 197).

\section{Trajetória histórica do GAJOP: o ontem e o hoje}

O GAJOP se configura desde o seu início como uma ONG de promoção e defesa dos direitos humanos, sem fins lucrativos, criada em 1981 no Estado de Pernambuco, período em que ainda vigorava a ditadura militar no Brasil, sendo esta uma época de grande mobilização da sociedade civil organizada pelo retorno da democracia.

O objetivo do GAJOP em seus primeiros anos foi desenvolver um trabalho prioritariamente voltado para a legalização da posse da terra na região metropolitana do Recife, tendo participado inclusive, das discussões sobre o Plano de Regularização das Zonas Especiais de Interesse Social, que garantiu a participação das entidades representativas dos moradores na elaboração dos planos de urbanismo e regularização fundiária na cidade de Recife. Frisa-se que nesse ínterim, em 1984, o GAJOP passa a atuar em parceria com o Centro de Cultura Luiz Freire $^{6}$ (CCLF), o que favoreceu, por um período de onze anos que ambas as organizações construíssem e efetivassem coletivamente seus projetos societários.

Destaca-se ainda que a ONG GAJOP nasce vinculada aos movimentos sociais cuja atuação tinha como cerne as lutas populares

\footnotetext{
${ }^{6}$ ONG fundada em 29 de agosto de 1972 que tem como missão a radicalização da democracia no Estado pela efetivação dos direitos humanos e combate às exclusões. Maiores informações podem ser obtidas no site: <www.cclf.com.br>.
} 
pela posse da terra, tal como ocorreu com outras ONGs na década de 1980, e em um contexto extremamente profícuo para as entidades da sociedade civil organizada, principalmente pelo fato da existência das condições objetivas para que o processo de redemocratização do Estado brasileiro fosse bem sucedido.

No entanto, decorrido esse espaço temporal, em 1995 os objetivos do GAJOP e do CCLF se modificaram, sobretudo mediante os avanços legislativos relativos ao objeto anterior, o que suscitou no GAJOP a necessidade de retomada de sua autonomia institucional, bem como do seu objeto de intervenção tendo sido eleito o Direito à Segurança e Justiça como questão central.

A partir dessa mudança passa a realizar um trabalho que denominou de "promoção e defesa dos direitos à justiça e à segurança pública, movido pela necessidade social de contribuir para o controle da violência"7, distanciando-se assim da temática de legalização da terra que foi seu foco de atuação nos anos iniciais.

Dessa forma, o período de 1995 a 1996 se constituem num momento em que o GAJOP reconquista sua autonomia institucional, passando a atuar em sede própria.

A organização assume uma prioridade política marcada pela opção de realizar uma ação política, não estatal, afirmando que não basta fazer defesa jurídica. A defesa de vítimas e testemunhas é dever do aparato institucional do Estado democrático de direito, de acordo com o teor da Constituição Federal de $1988^{8}$, e nesse âmbito institui sua nova missão institucional, mediante a elaboração de seu novo estatuto, focado na Segurança e Justiça seu novo campo de intervenção.

No intuito de colocar em prática as ações voltadas ao seu novo campo de intervenção, a missão é elaborada a fim de contribuir para a democratização e o fortalecimento da sociedade civil e do Estado na perspectiva da vivência da cidadania plena.

\footnotetext{
${ }^{7}$ Documento institucional denominado de "Apresentação da organização".

${ }^{8}$ Título V - Capítulo III da Constituição de 1988, os aspectos concernentes à segurança pública, onde no Art. 144 consta que a segurança pública é dever do Estado e deve ocorrer através das polícias federal, rodoviária federal, ferroviária federal, civil, militar e corpo de bombeiros militares.
}

A missão institucional demonstra que a ONG GAJOP tem o interesse de, para além da sociedade civil, incidir sobre o Estado na crença de que assim possa favorecer o alcance do que denomina de cidadania plena. Isto sem dúvida possibilita, no nosso entendimento, que atividades em parceria com o Estado se tornem amplamente viáveis, pois não contraria a missão e nem os objetivos institucionais que são: defender e promover os direitos humanos; contribuir para o respeito do direito à segurança e justiça, como condição essencial para plena validade da democracia e da cidadania; contribuir para a garantia e a preservação da vida, da integridade física e psicológica e da liberdade e, por fim, defender e promover em particular os direitos das crianças.

Outra questão relevante é que essa missão e objetivos são legitimados num período (década de 1990) de evidente dificuldade para as entidades da sociedade civil em se manter atuantes, ocasião em que o ideário neoliberal se encontrava em vigência no Brasil, e com a instituição do Plano Diretor de Reforma do Aparelho do Estado (PDRAE) sendo sua vertente mais evidente.

\section{GAJOP e Provita: uma história em comum}

De acordo com documentos institucionais ${ }^{9}$, os primeiros passos da ONG GAJOP para a construção do que posteriormente veio a se configurar no Provita ocorreram ainda em 1994, quando a instituição ainda se encontrava vinculada ao Centro de Cultura Luiz Freire.

Nesse período, o GAJOP e o CCLF identificaram a existência do medo da população em prestar informações à polícia e à Justiça o que, por conseguinte, favorecia a impunidade do ponto de vista das instituições citadas. Nessa época as duas ONGs realizaram pesquisa, cujo resultado demonstrava que a maioria dos 147 processos movidos contra o grupo de extermínio, pela $10^{a}$ Vara Privativa do Júri do Recife se encontravam paralisados por ausência de provas testemunhais.

Essa constatação também levou o GAJOP a perceber que a ausência de proteção efetiva

\footnotetext{
${ }^{9}$ GAJOP/CCLF - Gabinete de Assessoria Jurídica às Organizações Populares/Centro de Cultura Luiz Freire - Setembro, 1994; e Linha do Tempo Programa de Proteção a Testemunhas - Jayme Benvenuto.
} 
a testemunhas, inibe que estas compareçam ao Júri. Tal comprovação, associada aos elevados índices de violência no Estado de Pernambuco, favorece o interesse institucional em conhecer modelos de execução de programas de proteção desenvolvidos no exterior.

Com esse objetivo, em 1995 os membros do GAJOP realizaram visitas aos projetos nessa linha desenvolvidos na Inglaterra e na Holanda, bem como leram documentos e participaram de relatos orais dos especialistas em segurança oriundos da Itália e dos Estados Unidos.

Feitas as colocações anteriores, relembramos que o GAJOP em 1995 se torna entidade autônoma, que separada do CCLF molda a proposta de proteção a testemunhas. Para tanto, assina convênio de cooperação técnica com o Governo de Pernambuco ${ }^{10}$.

Ainda em 1995 a proposta de programa de proteção assume sua versão final, com seu esboço tendo sido discutido anteriormente com os oficiais da Polícia Militar, Delegados de polícia e integrantes do Ministério Público.

Nessa seara em janeiro de 1996, o Programa de Proteção tem seu início no estado de Pernambuco, tendo como objetivo principal a preservação da prova testemunhal. É importante observar que, no âmbito do Estado brasileiro, o Programa Nacional de Direitos Humanos (PNDH), de 13 de maio de 1996, se configura num dos fatores que favoreceu a aceitação do Provita como modelo de Proteção a Vítimas e Testemunhas Ameaçadas a ser implantado no Brasil.

Tal fato se revela quando no PNDH (1996, p. 8) lê-se, especificamente no capítulo que versa sobre a luta contra a impunidade, "A meta de apoiar a criação nos Estados de programas de proteção de vítimas e testemunhas de crimes, expostas a grave e atual perigo em virtude de colaboração ou declarações prestadas em investigação ou processo penal ${ }^{11}$ ".

Outra questão que nos pareceu favorecer essa aceitação pelo Estado do modelo Provita,

\footnotetext{
${ }^{10}$ Destaca-se que se encontrava presente como testemunha no ato da assinatura do convênio o Secretário-geral da Anistia Internacional, Pierre Sane.

${ }^{11}$ Dados obtidos no site da Secretaria Especial de Direitos Humanos, www.sedh.gov.br, onde consta o Decreto n. 1.904, de 13 de maio de 1996.
}

se refere ao fato de que a forma, com que foi proposto e veio a ser operacionalizado, estava de acordo com os requisitos que PDRAE propunha, na medida em que é a entidade da sociedade civil organizada que assume a execução do programa em tela.

Tal fato pode ser visto quando em sua primeira formatação escrita o GAJOP apresenta os entes responsáveis pelo programa, sendo eles: Secretaria de Segurança Pública; Secretaria de Justiça; Polícia Militar de Pernambuco; Secretaria de Trabalho e Ação Social e GAJOP, e suas respectivas responsabilidades, já estando posto nesse momento que a execução é função do GAJOP.

Além disso, o documento dispõe sobre as condições para atendimento de casos; situações admissíveis, formas e condições de atendimento; coordenação e supervisão do atendimento; atribuições dos beneficiários e integrantes da rede de proteção; Poder Judiciário e Ministério Público; incluindo ainda proposta de diretrizes para elaboração do manual de procedimentos e viabilidade econômica do programa.

Frisa-se que dentre essas instâncias, o GAJOP firma um convênio de cooperação técnica com o Ministério Público Estadual, que por sua vez inclui o Provita como uma de suas prioridades, definindo um promotor para acompanhar o programa. Sendo este um fato de relevância substancial para a consolidação do programa citado.

O GAJOP se compromete ainda a estabelecer uma rede de apoio e proteção a testemunhas, vítimas e familiares de vítimas da violência, para manter a integridade física de todos os seus usuários. Seu principal objetivo era promover a guarda e proteção dos beneficiários realizando o acompanhamento integral destes para auxiliá-los na adaptação ao programa.

Nesse âmbito, o significado de apoio às testemunhas e seus familiares são descritos como tendo todo auxílio tendente a fazer o beneficiário reunir as condições necessárias ao enfrentamento da violência, manifestado particularmente pelo encaminhamento ao atendimento psicológico e social, e por proteção entende-se como o ato de colocar o beneficiário do programa a salvo de qualquer violência capaz de retirar-Ihe as forças necessárias a contribuir 
com a prestação jurisdicional. (Documento Provita - GAJOP/CCLF) ${ }^{12}$.

Percebe-se, assim, que cabia a essa rede de apoio e proteção, articulada pelo GAJOP e formada por entidades e pessoas sensíveis à situação dos usuários, uma enorme responsabilidade pelos beneficiários do programa. Situação que, mesmo posteriormente, ainda está presente no discurso sobre o Provita, tendo sido inserida em Lei, configurando-se numa estratégia de proteção que perdura até os dias atuais.

Entre 1996 e 1997 o Provita Pernambuco se desenvolve, com uma meta inicial de atendimento de sessenta pessoas, e realiza um amplo processo de divulgação, que teve importante repercussão na mídia, ampliando sua rede de colaboradores.

O GAJOP, nesse período, também realizou campanhas para arrecadação de fundos, no que concerne à viabilidade econômica do Programa, além de recursos públicos, criou-se um fundo de apoio.

A criação desse fundo de apoio podia receber recursos advindos de doações de entidades governamentais, não governamentais, de assistência social e empresarial, além de loterias e outros meios legais, com as campanhas de arrecadação sendo realizadas para custear despesas não pagas com os recursos públicos.

Em 1997 ocorre na cidade do Recife o I Encontro Interestadual sobre Apoio e Proteção às Testemunhas e o I Seminário Nacional sobre Proteção a Testemunhas, estando presente neste último evento representantes do Programa Federal de Proteção a Testemunhas dos Estados Unidos; Procuradoria Nacional Antimáfia da Itália e Apoio a Vítimas de Violência da Inglaterra, eventos que favorecem a divulgação do Provita, bem como a capacitação e formação das instâncias envolvidas na proteção.

O período de 1997 e 1998 são marcados pela expansão do Provita para outros estados da federação. Nesse sentido é também o GAJOP que elabora um plano de nacionalização tendo objetivo principal fomentar a discussão entre representantes de grupos sociais locais e

\footnotetext{
12 O documento citado não possui especificação bibliográfica. Sendo um documento de domínio privado, para uso da pesquisadora foi autorizado verbalmente e por escrito (carta de anuência) pelos gestores institucionais.
}

de governos estaduais em torno da definição e implementação de um programa de apoio e proteção com base na realidade de cada estado e na experiência desenvolvida em Pernambuco ${ }^{13}$.

A partir desse momento, em 1998 a Secretaria Especial de Direitos Humanos (SEDH) foi possível assinar um convênio com o Governo de Pernambuco e assim efetivar o apoio formal ao GAJOP que já vinha desenvolvendo o Provita, sendo neste mesmo ano, assinado também, pelos estados da Bahia e do Espírito Santo, um convênio para implementação do PROVITA, após trabalho de articulação realizado pelo GAJOP nesses estados.

O processo de expansão progrediu de tal forma, que atualmente é executado em dezessete Estados da Federação, conforme descrito anteriormente, por entidades da sociedade civil e por Secretarias de Estado.

Em 1999 surge o Provita Brasil ${ }^{14}$ com o papel de promover a expansão e realizar o monitoramento do programa, contando para isso com o apoio do Programa das Nações Unidas para o Desenvolvimento (PNUD). Ao mesmo tempo em que permanece o investimento em capacitação para as equipes multidisciplinares, inclusive promovendo intercâmbio entre os técnicos das equipes de Pernambuco, Bahia e Espírito Santo.

Este também é o ano da promulgação da Lei Federal n. 9.807/99, que regulamenta o Provita, cujo formato contou com a intensa participação do GAJOP, que discutiu e propôs o conteúdo dos artigos do citado documento.

Na ótica do GAJOP, a instituição da Lei tornou realidade à definição de normas para a implementação dos programas estaduais e para a proteção dos réus e colaboradores da justiça. Também estrutura o modo de funcionamento, elenca as medidas compreendidas pelo Provita e define os requisitos para o ingresso.

Em 2000, o GAJOP constrói a primeira proposta de monitoramento o Provita, propiciando a análise da dimensão política, equipe, voluntariado e beneficiário do programa. Nesse

\footnotetext{
${ }^{13}$ Dado obtido no documento institucional "Expansão do Programa de Apoio e Proteção a Testemunhas, Vítimas e Familiares de Vítimas da Violência - $1^{\text {a }}$ fase".

${ }^{14}$ Atualmente o Provita Brasil recebeu a denominação de "Programa Federal e de Central" já tendo sido também denominado de "Central Nacional do Programa de Proteção".
} 
aspecto, destaca-se que o monitoramento contava com assessoria técnica nas áreas jurídica e psicossocial.

Além disso, neste ano ocorre o I Curso de Especialização em Direitos Humanos e Proteção a Testemunhas, ministrado pelo Departamento de Serviço Social da Universidade Federal do Rio de Janeiro (UFRJ), que teve como participantes os técnicos do Provita dos diversos Estados da Federação, inclusive do GAJOP.

O Provita amplia ainda mais suas demandas institucionais, e o GAJOP passa os anos subsequentes (2001 a 2003) dedicando-se a executar as atividades relativas a tal programa conforme previa os convênios de cooperação técnica, tendo participado nesse período, dos seminários e oficinas nacionais de capacitação técnica ${ }^{15}$, momento em que são tratados temas afetos ao programa.

Além disso, o GAJOP também participou de atividades em alguns estados, que efetivaram encontros para divulgar e tratar das questões do Provita localmente, bem como integrou os encontros do Fórum Permanente do Sistema Nacional de Proteção a Vítimas e Testemunhas Ameaçadas composto por representantes do Colégio Nacional dos Presidentes dos Conselhos Deliberativos e do Fórum de Entidades Gestoras/ Executoras.

A partir de 2005, o Provita passa por um processo de avaliação interna pelo GAJOP, como parte integrante do desenvolvimento institucional ocasionando mudanças significativas na forma de compreender e atuar com o programa, conforme veremos a seguir.

\section{A lógica de funcionamento do Provita}

Inicialmente é mister destacar que, conforme vimos anteriormente, o Provita tem seu marco legal datado de 13 de julho de 1999, mediante a promulgação da Lei 9.807/99, e a regulamentação do seu funcionamento descrito no Decreto-lei n. 3.518, datado de 20 de junho de 2000.

Isto posto podemos inferir, a partir das legislações específicas descritas anteriormente, que a porta de entrada do programa ocorre

\footnotetext{
${ }^{15}$ De acordo com registro institucional ocorreram cinco seminários e oficinas técnicas nacionais no período de 2001, 2002, 2004, 2006 e 2007.
}

mediante uma solicitação de ingresso que pode advir do próprio interessado; do Ministério Público; do Delegado de Polícia; do Juiz e dos demais órgãos públicos e entidades com atribuições de defesa dos direitos humanos, conforme especifica o Art. $5^{\circ}$ da Lei n. 9.807/99.

Em seguida, esse pedido é apresentado ao órgão executor, que, por sua vez, o remeterá para avaliação do Conselho Deliberativo, instruído da manifestação do Ministério Público e dos pareceres jurídicos e psicossociais do caso, sendo elaborado pela equipe técnica do programa, contratada pelo órgão executor para desempenhar as tarefas afetas ao Programa de Proteção.

Frisa-se que a decisão do Conselho Deliberativo pelo ingresso ou não da testemunha no programa também é feita a partir da análise de cinco pontos principais, conforme constam nos artigos $1^{\circ}$ e $2^{\circ}$ da Lei n. 9.807: situação de risco, colaboração da testemunha e/ou vítima no procedimento criminal, personalidade e conduta compatíveis com as restrições e normas do Provita; inexistência de limitações à liberdade e anuência do protegido.

Decidido pelo ingresso no Provita, a testemunha e seu núcleo familiar são retirados de seu local de moradia e inseridos, com observância de normas de sigilo e confidencialidade, em um novo local de moradia, onde receberão o apoio necessário para reconstrução de suas vidas.

\section{A execução do Provita pelo GAJOP e pelo Estado}

Realizada a explanação sobre o Provita e sua estrutura de funcionamento, é relevante que possamos nos deter sobre as características da "parceria" 16 a partir do que se encontra preconizado em Lei, e sobre o processo crítico que o GAJOP vem desenvolvendo desde 1998 e intensificado a partir de 2005 sobre as repercussões dessa relação para a entidade e para o Provita.

No que concerne à "parceria" é possível identificar no conteúdo do Decreto-lei a

\footnotetext{
${ }^{16}$ O termo "parceria" será tratado neste artigo sempre entre aspas, pois estamos partindo do pressuposto que para execução do Provita esta relação entre o Estado e a ONG GAJOP é desigual, com o peso da responsabilidade pendendo mais no sentido da entidade do que do Estado.
} 
legitimidade de sua efetivação, quando se encontra descrito no Art. $1^{\circ} \S 1^{\circ}$ que: A União, os Estados e o Distrito Federal poderão celebrar convênios, acordos, ajustes, ou termos de parceria entre si ou com entidades não governamentais objetivando a realização dos programas.

Para concretizar essa finalidade de execução do Provita, desde o início do programa em 1996, a "parceria" é firmada através da assinatura de um Convênio de Cooperação Técnica e de Prestação de Serviços que tem atualmente, em geral, a seguinte formatação: Secretaria de Direitos Humanos que firma convênio com as Secretarias Estaduais de Justiça ou Segurança Pública, que por sua vez firmam convênio de parceria com entidades não governamentais para que estas últimas executem o programa de proteção, sendo a responsável direta por colocar em prática as estratégias de proteção aos usuários do programa.

Os convênios são constituídos por cláusulas que versam sobre as obrigações de cada ente no âmbito do Provita. Além disso, existe o Plano de Trabalho, instrumento onde consta a descrição do projeto, título, identificação e justificativa do objeto, cronograma de execução financeira com um cronograma de desembolso entre outros itens, orientando os entes conveniados sob o processo normativo ${ }^{17}$ que rege a execução desse programa.

Dessa forma, fica evidenciado que o convênio é firmado entre os entes estatais e entre estes e entidades não governamentais. Dentre essas organizações podemos perceber a existência de fundações, ONGs e Associações. Tal fato apenas vem corroborar com o entendimento de que são uma realidade convênios com entidades públicas não estatais para execuções das atribuições do Estado.

Essas mesmas entidades assumem no Provita um papel central: a execução. Portanto, os desafios cotidianos da operacionalização desse programa surgem, tendo como o elemento de maior relevância a falta de apoio integral do Estado nesta mesma execução, pois na medida em que o Estado não cumpre com suas obri-

\footnotetext{
${ }^{17}$ De acordo com a Coordenadora do Setor Administrativo Financeiro do GAJOP, esse convênio é elaborado apoiado no conteúdo do documento "Instrução Normativa n. 01".
}

gações nessa relação de "parceria", o peso da responsabilidade sob a sociedade civil se amplia.

Nesse contexto, evidenciamos que promover a segurança dos usuários, efetuar interlocução com os órgãos públicos para atendimento das suas demandas, efetivar traslado das testemunhas entre outras atribuições têm se tornado um papel cada vez mais complicado para essas entidades.

Comentamos este aspecto, pois são esferas da execução que não dependem exclusivamente da ação das entidades da sociedade civil. Na medida em que o recurso destinado ao programa demora a ser depositado para entidade executora, as ações do programa sofrem descontinuidade.

A falta de regulamentação e de ações por parte do Estado que legitimem o acesso das testemunhas e seus familiares aos serviços disponibilizados pelos Governos federal, estadual e municipal de forma a minimizar os riscos de serem localizados também se configuram num aspecto que acarreta complicações.

Diante do reconhecimento dessas dificuldades, a ONG GAJOP iniciou, em 2005, um intenso processo de desenvolvimento institucional, que incluiu a avaliação dos programas que executa, e no tocante ao Provita, reconheceu as dificuldades de uma entidade da sociedade civil na execução de um programa do porte deste, nas condições atuais em que a "parceria" com o Estado se encontra estabelecida.

Para iniciar esse processo avaliativo, o GAJOP se propôs a desenvolver uma ação crítica e ao mesmo tempo propositiva acerca da proteção a testemunhas após dez anos de existência do citado programa. Nesse intuito buscou organizar os elementos de uma análise crítica do PROVITA e a repercussão que a execução do programa pelo GAJOP assume na missão, no projeto político da entidade e nos valores e crenças dos profissionais contratados para desenvolver 0 programa..$^{18}$

Sublinhamos que a avaliação do Provita realizada pelo GAJOP levou em consideração a relação da entidade com o Estado, com entidades da sociedade civil (local e executoras do

\footnotetext{
18 Dados advindos do documento institucional "Memória do GAJOP - Projeto Político - Institucional”.
} 
programa) e com as dimensões do programa desenvolvidas em seu interior. Tal avaliação teve várias fases, que resultaram na elaboração de documentos por parte das equipes envolvidas culminando em um relatório final, que por sua vez passou por três versões até sua finalização, contando para tanto com a participação de profissionais externos que contribuíram com as reflexões.

$\mathrm{Na}$ versão final do relatório avaliativo ${ }^{19}$, podemos identificar o nível de inquietação que o GAJOP vivencia em relação à execução do Provita, quais sejam:

1) Estamos verdadeiramente contribuindo, enquanto entidades da sociedade civil, atores pertencentes à esfera pública não estatal, com essa política de proteção? 2) Estamos, enquanto entidades gestoras do Programa, atuando de forma tal que nossa articulação permita imprimir uma direção social à política de proteção, sendo capazes de interferir, por exemplo, nas diretrizes, sejam elas orçamentárias, políticas ou técnicas? 3) Podemos dizer que o conjunto de entidades gestoras do Provita compõe a base social desta política? (p. 9).

Mas em outro relatório ${ }^{20}$ sobre tal programa, elaborado com base nos diálogos e documentos produzidos pelas equipes e pelo GAJOP, ficam evidenciadas algumas das dimensões da problemática da execução. A questão da gestão administrativa, técnica e política se tornam um problema central na relação com o Estado. "Um desses aspectos é o fato do Estado determinar unilateralmente regras de funcionamento do programa, especialmente no se refere à questão financeira."

Por esse prisma, a lógica de "parceria" utilizada na execução, na ótica dos integrantes do Provita no GAJOP, fica extremamente comprometida, haja vista a identificação da ausência de espaços para dialogar e negociar sobre o programa. Isto decorre da impressão que o Es-

\footnotetext{
${ }^{19}$ Documento "Re(construindo) Babel: uma reflexão sobre a execução do Provita" de autoria Marcela Valença e Paulo Aguiar, em 15 de maio de 2007.

${ }^{20}$ Dados advindos do documento de uso privado do GAJOP denominado, "Segunda Versão do Relatório", elaborado por Evanildo Barbosa em novembro de 2006.
}

tado parece não estar levando em consideração as proposições da entidade nos momentos de negociação e de vigência do convênio que formalmente é de cooperação técnica, mas que no plano da realidade parece seguir num sentido contrário.

Nesse relatório citado também deixa evidenciado algumas das necessidades de ação que a entidade precisa adotar para tentar modificar a tônica da relação com o Estado, sendo elas:

- Necessidade de estabelecer diálogo e relações com o Estado, sem se confundir com ele, o que significa refletir sobre a operação de política de direitos humanos (Provita na ótica do GAJOP) num ambiente de Estado Mínimo;

- Retomar o diálogo com as entidades da sociedade civil organizada que compõe o Provita para discutir o lugar da sociedade civil neste programa.

Ou seja, o caminho proposto indica o desejo de manter relação com o Estado, na perspectiva de constituir o Provita, numa política de direitos humanos como a entidade preconizou na ocasião da elaboração do programa, e ampliar a discussão para fora dos muros do GAJOP, socializando-a para as demais entidades que compõem o fórum de entidades gestoras ${ }^{21}$.

Nota-se ainda que diversos outros aspectos foram abordados nessa avaliação, no entanto o que consideramos mais importante é que o GAJOP iniciou um processo de crítica sobre o lugar da sociedade civil no Provita, sendo necessário rearticular os diálogos com as demais entidades que executam o programa e com as entidades locais (estado de Pernambuco) no intuito de coletivamente poder realizar a reflexão e propor alternativas às dificuldades existentes no programa.

Outra questão tratada na avaliação realizada pelo GAJOP sobre o Provita e que chama a atenção por se configurar num outro aspecto que remete à relação de "parceria" fortalecendo

\footnotetext{
${ }^{21}$ Esse fórum passou por um período desarticulado, com a rearticulação sendo possível após intenso trabalho do GAJOP, que aproveitou o momento do encontro ocorrido em Fortaleza para "X Reunião Nacional dos Programas de Proteção", onde se encontravam presentes representantes das entidades executoras do Provita, para ampliar a discussão interna que se encontrava ocorrendo no GAJOP.
} 
o propósito de transferir para as organizações não governamentais responsabilidades que a priori seriam do Estado se refere à rede solidária de proteção.

A finalidade do GAJOP, ao propor a rede de proteção, foi garantir o que denominou de "base social do Provita", que teria na solidariedade e no voluntariado de pessoas e entidades comprometidas com os direitos humanos sua lógica de ação. No entanto, o que se percebe atualmente é a desvirtuação desse propósito, na medida em que a rede não realiza o que preconiza, de acordo com o relatório de avaliação final:

Com ênfase na dinâmica dos procedimentos do Programa e, em última análise, vinculada ao do exercício do voluntariado colaborativo com o Estado e complementar à execução dos procedimentos do sistema jurídico, por tempo determinado, apenas afirma a ideia de cidadania provisória. O conjunto de atividades técnicas não incorpora a construção de vínculos com as Entidades e, em termos amplos, com a sociedade civil local, uma vez que a Rede faz uma trajetória própria, dissociada dos acúmulos de experiências que fazem a história de lutas da sociedade civil pelos direitos humanos, democracia e cidadania. A ausência das referências teórico-metodológicas indispensáveis à sua (re) construção, a ideia da Rede Solidária não conquista a importância do lugar ocupado por uma base social da política de proteção. (p. 12).

Sabemos que as entidades da sociedade civil sempre buscaram manter uma postura solidária e voluntária para ampliar e consolidar suas ações, através de redes, o que é muito positivo. Mas o problema que surge em relação a esse aspecto, na nossa compreensão, é quando essa solidariedade/voluntariedade passa a ser instrumentalizada, deixando de ser um ato voluntário; feito com quem e para quem se deseja, para ser balizado pelo Termo de Compromisso, com a tônica de obrigatoriedade se fazendo presente.

Nesse sentido, parece que o ato voluntário, agora "obrigatório", retira do âmbito dos direitos as garantias constitucionais de acesso a bens e serviços prestados pelo Estado, pois na medida em que o Estado passa a atuar numa lógica de complementaridade, ele deixa de cumprir adequadamente com suas funções, tendo ainda como argumentar que as responsabilidades pela precariedade dos serviços são das entidades não governamentais.

Ainda sobre esse assunto Montaño (2002) afirma que ocorre uma modificação na resposta das sequelas da questão social, passando a se assentar agora nos valores da solidariedade voluntária e local, da autoajuda e da ajuda mútua, como podemos ver abaixo:

Nesta passagem, a função social da resposta às refrações da 'questão social' deixa de ser no projeto neoliberal, responsabilidade privilegiada do Estado, e por meio deste conjunto da sociedade, e passa a ser agora de autorresponsabilidade dos próprios sujeitos portadores de necessidades, e da ação filantrópica, 'solidária-voluntária', de organizações e indivíduos. A resposta às necessidades sociais deixa de ser uma responsabilidade de todos (na contribuição compulsória do financiamento estatal, instrumento de tal resposta) e um direito do cidadão, e passa agora, sob a égide neoliberal, a ser uma opção do voluntário que ajuda o próximo, e um não direito do portador de necessidades, o cidadão pobre. (p. 22).

Situação esta que desafia diariamente as entidades da sociedade civil executoras do programa em cada estado, haja vista a diversidade de pessoas que ingressam no programa, cada uma requerendo atenção especial às suas especificidades (alcoolistas, usuários de entorpecentes, usuários com histórico na criminalidade, com deficiência física, etc.), bem como a ausência de apoio estatal para legitimar e agir em prol da criação dos meios que garantam os subsídios ao acesso sigiloso desses usuários aos bens e serviços sociais.

Além disso, as entidades executoras têm que responder por problemas como ausência de recursos, perante os usuários e equipe contratada, nos períodos em que se processa a renovação do convênio, tendo também a entidade que assumir e lidar com as questões dos direitos trabalhistas dos profissionais das equipes, pois nisto o Estado não tem responsabilidade direta, uma vez que a contratação dos profissionais é feita pelas entidades executoras do Provita.

De acordo com o exposto, o que parece é que o Estado tem deixado a desejar em relação às suas atribuições, no que concerne à "parceria" com as entidades não governamentais na execução do Provita, uma vez que, no geral, o 
Estado tem se restringido a efetuar o repasse dos recursos aos Governos estaduais; a supervisionar e fiscalizar se ao final de cada convênio os recursos foram utilizados conforme acordado; a promover oficinas de capacitação técnica e seminários de proteção a testemunhas, uma vez a cada ano.

Esses são apenas alguns dos problemas que as entidades da sociedade civil vivenciam e que precisam ser analisados, discutidos e propostos encaminhamentos, sob pena de se chegar a um esgotamento de possibilidades que pode culminar em um intenso risco para essas entidades.

\section{Considerações finais}

No discurso dessa entidade da sociedade civil sobre a execução do programa citado sempre esteve presente como objetivo sensibilizar o Estado (União e Estados-membros) a desenvolver autonomamente um sistema de apoio e proteção às testemunhas e seus familiares, reconhecendo que embora se trate de atribuição originária do Estado, cabe também às entidades da sociedade civil participar desse programa.

Conforme o exposto, os aspectos significativos para a compreensão do tema em discussão nos parecem ter sido os seguintes: O Provita se configura num modelo que recebeu embasamento de experiências internacionais; foi elaborado por entidade da sociedade civil; é executado pela sociedade civil mediante convênio de cooperação técnica com o Estado; e nasceu com o intuito de atuar na perspectiva dos direitos humanos, ao menos no que se refere ao ponto de vista da entidade que o fomentou.

Tendo em vista essas considerações mais uma vez ressaltamos que as condições objetivas estavam dadas para a participação direta na execução de programas como o Provita, por entidades da sociedade civil. Também é necessário frisar que o mais interessante nesse contexto é que a ideia, o formato da proposta e a participação ativa da sociedade civil foram gestados por uma ONG, num período de evidente consolidação do ideário neoliberal no Brasil.

Possivelmente uma estratégia desse porte ocasiona consequências no cotidiano dessa execução para as pessoas diretamente envolvidas, mas para compreender essa questão é preciso antes entender quais são os pilares estruturantes do Provita e em quais bases estão fincadas a "parceria" entre o Estado e a ONG GAJOP, que assume papel de destaque no processo de criação e evolução do programa de proteção.

É preciso que as organizações não governamentais se mantenham atentas e informadas para que possam realizar as críticas construtivas e evitar que sucumbam às tentações de acreditar que as relações entre o Estado e sociedade civil não sejam permeadas de tensões, pois sem prestar atenção a essas questões podem correr o risco de serem cooptadas e perderem sua identificação com as lutas populares.

\section{Referências}

ALVES, G. Nova Ofensiva do capital, crise do sindicalismo e as perspectivas do trabalho - o Brasil nos anos noventa: In: TEIXEIRA, F. J. S.; OLIVEIRA, M. A. de. (Org.). Neoliberalismo e Reestruturação Produtiva. São Paulo: Cortez; Fortaleza: Universidade do Ceará, 1996.

ANDERSON, P. Balanço do neoliberalismo. In: SADER, E. \& GENTILI, P. (Orgs.). Pós-neoliberalismo: as políticas sociais e o Estado democrático. Rio de Janeiro: Paz e Terra, 1995.

BEHRING, E. R. Brasil em contra-reforma: desestruturação do Estado e perda de direitos. São Paulo: Cortez, 2003.

BRASIL, PRESIDÊNCIA DA REPÚBLICA. Plano Diretor da Reforma do Aparelho do Estado. Brasília, Câmara da Reforma do Estado, 1995.

BRASIL, PRESIDÊNCIA DA REPÚBLICA. Lei $n$. 9807 de 13 de julho de 1999. Disponível em: www. planalto.gov.br/ccivil_03/leis//9807.htm Acesso em: 01/12/2014.

BRASIL, PRESIDÊNCIA DA REPÚBLICA. Decreto $n$. 3.518, de 20 de junho de 2000. Disponível em: www. planalto.gov.br/ccivil_03/decreto/D3518.htm Acesso em: 01/12/2014.

COGGIOLA, O. KATZ, C. Neoliberalismo ou crise do capital? São Paulo: Ed. Xamã, 1996.

DURIGUETTO, M. L. A Sociedade civil, esfera pública, terceiro setor: a dança dos conceitos. Revista Quadrimestral Serviço Social e Sociedade, v. 26, n. 81, p. 82-101. Mar. 2005.

FERNANDES, L. Neoliberalismo e reestruturação produtiva. In: SADER, E.; GENTILI, P. (Orgs.). Pós- 
neoliberalismo: as políticas sociais e o Estado democrático. Rio de Janeiro: Paz e Terra, 1995. p. 54-61.

FRIEDMAN, M. Capitalismo e Liberdade. Tradução de Luciana Carli. Rev. sobre a edição de 1982 e tradução do prefácio de 1982 de Nestor Deola. 3. ed. São Paulo: Nova Cultural, 1988.

HAYEK, F. A. Von. O caminho da servidão. Tradução e revisão Anna Maria Capovilla, José Ítalo Stelle e Liane de Morais Ribeiro. Rio de Janeiro: Biblioteca do Exército, 1994. 221 p.

HARVEY, D. Condição pós-moderna. Tradução de Adail Ubirajara Sobral e Maria Stela Gonçalves. São Paulo: Edições Loyola, 1992.

MARTINI, P. Proteção especial a vítimas, testemunhas e aos réus colaboradores. Porto Alegre: Síntese, 2000.

MONTAÑO, C. Terceiro setor e questão social: crítica ao padrão emergente de intervenção social. São Paulo: Cortez, 2002.

MONTEIRO, V. B. PROVITA: Uma proposta de política pública. Revista Direitos Humanos GAJOP, Recife, v. 3, n. 7, p. 17, jan./jul. 2001.

MORAES, P. R. PROVITA: Uma Política Pública de Proteção a Testemunhas. João Pessoa: Ed. da UFPB, 2002.

PEREIRA, A. A. (Org.). Sistema Nacional de Assistência a Vítimas e Testemunhas: Programas e Legislação Federal. Brasília, Ministério da Justiça, 2001.

TEIXEIRA, F. J. S.; OLIVEIRA, M. A. de. (Org.). Neoliberalismo e Reestruturação Produtiva. São Paulo: Cortez; Fortaleza: Universidade do Ceará, 1996. 